\title{
IMPLEMENTASI METODE AHP DAN PROMETHEE PADA SPK PEMILIHAN HOTEL
}

\author{
Eka Larasati $^{1}$, Elok Nur Hamdana ${ }^{2}$, Anisa Meiyanti Hutami ${ }^{3}$ \\ 1,2,3 Teknik Informatika, Teknologi Informasi, Politeknik Negeri Malang \\ ${ }^{1}$ eka.larasati@polinema.ac.id, ${ }^{2}$ elokhamdana@polinema.ac.id, ${ }^{3}$ anisameiyantihutami@gmail.com
}

\begin{abstract}
Abstrak
Perkembangan hotel di Kota Batu sedang melaju pesat, hal tersebut dapat dlihat dari banyaknya hotel baru yang dibangun dan jumlah tamu yang menginap di hotel. Kondisi tersebut dapat menimbulkan kesulitan bagi wisatawan dalam memilih hotel, sehingga sering kali wisatawan tidak mendapatkan hotel sesuai dengan prioritas keinginan yang mereka tentukan. Oleh karena itu, peneliti meneliti dan mengembangkan sistem pendukung keputusan yang menerapkan metode AHP untuk mengukur konsistensi kriteria yang ditentukan oleh pengguna khususnya dalam penelitian ini adalah wisatawan. Metode Promethee untuk menghitung dan meranking daftar hotel yang paling sesuai dengan keinginan wisatawan. Pada penelitian yang telah dilakukan terdapat beberapa kekurangan dari sistem yaitu basis data yang tidak bisa diperbaharui secara langsung dan ketidakjelasan alur program, dalam hal ini wisatawan tidak perlu mengetahui semua alur perhitungan sistem.
\end{abstract}

Kata kunci : Sistem Pendukung Keputusan, AHP, Promethee

\section{Pendahuluan}

Kota Batu termasuk dalam 7 Kota terindah di Indonesia versi Kumparan.com pada 7 Agustus 2018 (Rasputri, 2018). Kota Batu memiliki sejuta pesona keindahan berupa masyarakat yang ramah, budaya lokal yang masih dipertahankan, objek wisata alami maupun buatan. Selaras dengan hal tersebut, pembangunan hotel yang menjadi salah satu sektor pendukung wisata juga terus digalakan. Terdapat penambahan 1000 kamar sejak 2015 sampai Februari 2018 menurut Perhimpunan Hotel dan Restoran Indonesia (PHRI) Batu melalui malangtimes.com (Richa, 2018).

Kebutuhan masyarakat akan informasi mengenai hotel terus meningkat, seiring dengan laju pertumbuhan hotel. Keberagaman hotel membuat wisatawan bingung dalam menentukan pilihan sesuai dengan prioritas atau bobot kriteria yang diinginkan, sehingga diperlukan suatu sistem yang dapat membantu wisatawan dalam memilih hotel. Dalam system ini admin dapat melakukan pengelolaan data hotel, mulai dari nama, bintang, fasilitas, harga dan strategis. Sistem dapat dimanfaatkan oleh wisatawan dengan memasukkan bobot atau prioritas pada kriteria sesuai dengan keinginan. Rekomendasi hotel akan ditampilkan oleh sistem, sehingga dapat membantu wisatawan untuk mendapatkan informasi yang sesuai dengan keinginan wisatawan.

Terdapat dua metode yang diimplementasikan pada sistem yakni Analytic Hierarchy Process (AHP) dan Preference Ranking Organizational Method for Enrichment Evaluation (Promethee). Perhitungan bobot atau prioritas setiap kriteria dapat dihitung menggunakan metode AHP. Kriteria yang digunakan dalam sistem ini berupa bintang, fasilitas harga dan strategis. Alternatif dihitung menggunakan metode Promethee, karena cocok untuk menghitung alternatif dengan banyak kriteria. Berdasarkan faktor di atas, maka kedua metode sangat cocok untuk di implementasikan dalam sistem.

Berdasarkan permasalahan yang telah di jelaskan, maka penulis mengangkat masalah tersebut menjadi skripsi dengan judul sebagai berikut: Implementasi Metode AHP dan Promethee pada Sistem Pendukung Keputusan Pemilihan Hotel Bagi Wisatawan di Kota Batu.

\section{Tinjauan Pustaka}

\subsection{Hotel}

Menurut SK Menparpostel No.KM 34/HK 103/MPPT-87 dalam Sigit Purnomo, hotel adalah suatu jenis akomodasi yang mempergunakan sebagian atau seluruh bangunan guna menyediakan jasa penginapan, makanan dan minuman serta jasa penunjang lainnya bagi umum yang dikelola secara komersial (Purnomo, 2016).

Pengklasifikasian hotel berbintang menurut SK Menparpostel RI No. PM/PW 301/PHB-77, terbagi menjadi lima yaitu (Dicky Sumarsono, 2014), hotel bintang 1 , hotel bintang 2 , hotel bintang 3 , hotel bintang 4 dan hotel bintang 5. Detail pengklasifikasian hotel, terdapat pada tabel berikut: 
Tabel 1. Klasifikasi Hotel Berbintang

\begin{tabular}{|c|c|}
\hline Kategori & Keterangan \\
\hline Bintang 1 & $\begin{array}{l}\text { Hotel ini memiliki sekurang-kurangnya } \\
15 \text { kamar, restoran dan satu kamar } \\
\text { kategori suitte room. Kamar kategori } \\
\text { ini memiliki dua kamar tidur untuk dua } \\
\text { orang yang berisi ruang tamu, ruang } \\
\text { makan dan dapur berukuran kecil. }\end{array}$ \\
\hline Bintang 2 & $\begin{array}{l}\text { Kategori bintang } 2 \text { memiliki sekurang- } \\
\text { kurangnya } 20 \text { kamar, restoran dan dua } \\
\text { kamar kategori suite room. Kamar } \\
\text { kategori ini memiliki dua kamar tidur } \\
\text { untuk dua orang yang berisi ruang } \\
\text { tamu, ruang makan dan dapur } \\
\text { berukuran kecil. }\end{array}$ \\
\hline Bintang 3 & $\begin{array}{l}\text { Hotel memiliki } 30 \text { kamar, retoran, dan } \\
\text { tiga kamar suite room. Kamar kategori } \\
\text { ini memiliki dua kamar tidur untuk dua } \\
\text { orang yang berisi ruang tamu, ruang } \\
\text { makan dan dapur berukuran kecil. }\end{array}$ \\
\hline Bintang 4 & $\begin{array}{l}\text { Kamar yang berjumlah minimal } 50 \text {, } \\
\text { restoran dan empat kamar kategori } \\
\text { suite room. Kamar kategori ini } \\
\text { memiliki dua kamar tidur untuk dua } \\
\text { orang yang berisi ruang tamu, ruang } \\
\text { makan dan dapur berukuran kecil. }\end{array}$ \\
\hline Bintang 5 & $\begin{array}{l}\text { Jumlah kamar minimal } 100 \text { unit dengan } \\
\text { minimal lima kamar kategori suite } \\
\text { room. Kamar kategori ini memiliki dua } \\
\text { kamar tidur untuk dua orang dengan } \\
\text { ruang tamu, ruang makan dan dapur } \\
\text { berukuran kecil. Hotel juga harus } \\
\text { dilengkapi dengan restoran. }\end{array}$ \\
\hline
\end{tabular}

\subsection{Sistem Pendukung Keputusan}

Decision Support System (DSS) yang dalam Bahasa Indonesia Sistem Pendukung Keputusan (SPK) merupakan suatu sistem yang mampu membantu pengambilan keputusan dalam masalah semi terstruktur atau tidak terstruktur. Menurut Mann dan Watson dalam Ferinda Yuamita, Sistem Pendukung Keputusan merupakan suatu sistem yang interaktif dan membantu proses pengambilan keputusan. Pemanfaatan data dan model-model keputusan, untuk memecahkan masalah yang bersifat terstruktur atau semi terstruktur (Ferinda Yuamita, Widya, Yardin, Zoelverdi, 2011). a. Data

Komponen SPK terdiri atas 3 bagian yaitu:

Database Management merupakan sub sistem dalam suatu basis data, SPK memerlukan adanya data yang relevan dengan pokok permasalahan yang hendak diselesaiakan. Hal tersebut bertujuan agar system dapat bekerja sesuai dengan tujuan pembuatannya. Data dapat berasal dari luar berupa masukan oleh user, atau dari dalam sistem berupa hasil olah data masukan. b. Model

Model base atau suatu model yang dapat mepresentasikan permasalah kedalam format kuantitatif (seperti pemodelan matematika) sebagai dasar pengambilan keputusan. Termasuk di dalamnya objektif atau tujuan dari permasalahan, komponen terkait constraints atau batasan, dan hal terkait lain. Model base memungkinkan pengguna menganalisa alternatif secara utuh melalui pengembagan dan pembandingan.

c. Grapical User Interface

Pengelolaan dialog atau graphical user interface merupakan penggabungan dari Database Management dan Model Base. User interface menampilkan keluaran sistem bagi pengguna yang dapat digunakan untuk memasukkan data. Sehingga sistem dapat menerima masukkan oleh user, kemudian akan diproses oleh sistem.

\subsection{Analutical Hierarcy Process (AHP)}

Thosmas L. Saaty pada Wharton School of Economics, Amerika Serikat (1971-1915) dalam Pengambilan Keputusan Manajemen Menggunakan Metode AHP oleh Sambudi Hamali, S.ST, M.M (Hambali, 2015). Mengembangkan metode analisis keputusan dengan nama Analytical Hierarcy Process $(A H P)$. Pada dasarnya metode ini digunakan untuk memecah situasi ke dalam bagian-bagian komponen atau variable ke dalam suatu susunan hirarki. Input atau masukkan utamanya adalah persepsi manusia.

Adapun tahapan dari AHP adalah :

a. Menyusun secara hirarki

Sebagai langkah awal dalam metode $A H P$ adalah memisahkan keputusan menjadi hirarki tujuan, kriteria dan alternatif.

b. Menetapkan prioritas

Penyusunan hirarki kemudian diikuti dengan penetapan atau pemilihan prioritas untuk setiap kriteria, pemilihan menggunakan skala banding secara berpasangan. Berikut tabel untuk menjelaskan skala banding secara berpasangan

Tabel 2. Skala Banding Berpasangan

\begin{tabular}{|c|l|}
\hline Nilai & \multicolumn{1}{|c|}{ Keterangan } \\
\hline 1 & Kedua elemen sama pentingnya (equal) \\
\hline 3 & $\begin{array}{l}\text { Elemen yang satu sedikit lebih penting } \\
\text { dari pada elemen yang lainnya } \\
\text { (moderate) }\end{array}$ \\
\hline 5 & $\begin{array}{l}\text { Elemen yang satu lebih penting } \\
\text { daripada elemen yang lainnya (strong) }\end{array}$ \\
\hline 7 & $\begin{array}{l}\text { Satu elemen jelas lebih mutlak penting } \\
\text { daripada elemen lainnya(very strong) }\end{array}$ \\
\hline 9 & $\begin{array}{l}\text { Satu elemen mutlak penting daripada } \\
\text { elemen lainnya (extreme) }\end{array}$ \\
\hline $2,4,6,8$ & $\begin{array}{l}\text { Nilai-nilai antara dua nilai } \\
\text { pertimbangan yang berdekatan }\end{array}$ \\
\hline
\end{tabular}




\section{c. Konsistensi}

Proses Analytical Hierarchy Porcess (AHP) mencakup pengukuran konsistensi pada pemberian nilai dalam pembandingan antar objek. Ketidakkonsistensian dapat timbul karena miskonsepsi dalam melakukan penyusunan hirarki, kekeliruan penulisan angka, kekurangan informasi, dan lain-lain. Pengukuran secara logis dapat dilakukan dengan perhitungan Consistecy Ration (CR), jika nilai $C R$ dianggap konsisten maka nilai kurang dari 0,1 (Hambali, 2015).

\subsection{Preferences Ranking Organization Method for Encrichment Evaluation (Promethee)}

Suatu metode penentuan urutan atau prioritas dalam analisis multikriteria, menggunakan bobot dari masing-masing kriteria yang kemudian diolah untuk menentukan urutan alternatif. (Tamara, 2017) Langkah-langkah perhitungan metode Promethee adalah : (W, 2017)

a. Menentukan beberapa alternative

b. Menentukan beberapa kriteria

c. Menentukan dominasi kriteria

d. Menentukan tipe penilaian

e. Menentukan tipe preferensi untuk setiap kriteria

f. Memberikan nilai threshold

g. Perhitungan Leaving Flow, Entering Flow dan Net Flow

h. Hasil pengurutan berdasarkan ranking

\subsection{Codeigniter}

Codeigniter adalah framework PHP open source dengan menerapkan metode MVC (Model, View, Controller), hal tersebut berdasarkan pada Betha Sidik dalam Mara Destiningrum, Qadhli Jafar Adrian (2017). Situs resmi codeigniter (2002) dalam Mara Destiningrum, Qadhli Jafar Adrian (2017) menyebutkan bahwa codeigniter merupakan framework PHP yang kuat dengan sedikit bug (Mara Destiningrum, Qadhli Jafar Adrian, 2017).

Rick Ellis merupakan CEO Ellislab, Inc. sekaligus pengembang framework codeigniter, beberapa kelebihan framework codeigniter Gratis (Open-Source), berukuran kecil, menerapkan konsep MVC. Konsep MVC terdiri atas komponen sebagai berikut :

a. Model

Model berhubungan dengan data dan interaksi dengan database. Di dalam model berisi class dan fungsi yang digunakan untuk memanipulasi data seperti menambah, memperbaharui dan menghapus yang berupa perintah-perintah query SQL (Tamara, 2017).

b. View

View berhubungan dengan segala sesuatu yang ditempatkan untuk end-user, dapat berupa halaman web (Tamara, 2017). Halaman web dapat berupa template atau kode PHP untuk menampilkan data pada browser (Mara Destiningrum, Qadhli Jafar Adrian, 2017). Sehingga user dapat memanfaatkan fitur-fitur yang teradapat dalam website dengan lebih maksimal.

c. Controller

Controller merupakan penghubung antara Model dan View, didalam controller terdapat class dan fungsi-fungsi yang memproses permintaan dari View ke Model. (Tamara, 2017)

\section{Metodologi}

\subsection{Metodologi Pengambilan Data}

Tahapan penelitian dimulai dengan melakukan pengumpulan data, pada tahap ini dilakukan pengumpulan data berupa data hotel berbintang yang ada di Kota Batu. Data tersebut di dapat dari Dinas Pariwisata Kota Batu dan website resmi hotel.

Setelah data hotel dikumpulkan selanjutnya data data hotel ini dipadukan antara data dari Dinas Pariwisata dan data dari website hotel. Sehingga didapatkan susunan data yang sesuai dengan kebutuhan sistem.

\subsection{Metode Pengolahan Data}

Setelah data hotel tersedia dilakukan proses selanjutnya adalah analisa data menggunakan metode waterfall. Tahapan analisa ini juga untuk menentukan pembagian intrumen penilaian pada setiap kriteria, dalam hal ini yaitu bintang, fasilitas, harga dan strategis. Tahapan berikutnya adalah desain, yang terdiri atas perancangan model-model yang akan diimplementasikan dalam tahap coding, testing dan maintenance.

Tahapan ini juga dilakukan perhitungan data secara manual, guna mengetahui kesesuaian data yang didapat dengan metode yang akan di implementasikan pada Sistem Pendukung Keputusan Pemilihan Hotel bagi Wisatawan di Kota Batu.

\subsection{Metode Pengujian}

Metode Pengujian yang dilakukan oleh penulis untuk menguji sistem secara keseluruhan dilakukan dengan cara pengujian fungsional dan uji coba perhitungan. Pengujian dilakukan dengan menjalankan fitur-fitur yang terdapat dalam sistem dan melihat kesesuaian antara rancangan pengembangan dengan implementasi yang telah dilakukan. Proses uji coba perhitungan dilakukan untuk melihat kesesuaian antara hasil perhitungan yang diolah system dengan perhitungan yang dilakukan secara manual. Jika kedua perhitungan sesuai maka system dapat dinyatakan berjalan dengan benar. 


\section{Perancangan \\ 4.1 Deskripsi Sistem}

Sistem Pendukung Keputusan Pemilihan Hotel Bagi Wisatawan di Kota Batu ini, menerapkan metode AHP untuk melakukan pengujian tingkat konsistensi terhadap bobot. Kemudian dilanjut dengan metode Promethee untuk melakukan perangkingan dari semua data hotel yang terdapat dalam basisdata sistem.

\subsection{Analisa Sistem}

Dalam penelitian ini, alur sistem yang akan dijalankan dapat dijelaskan pada Gambar 1 dibawah ini :
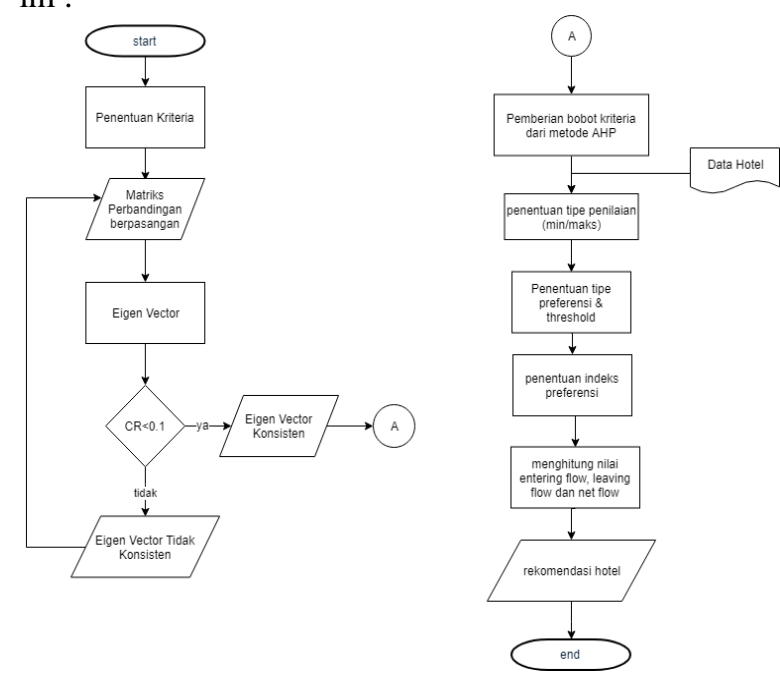

Gambar 1. Flowchart Sistem Pendukung Keputusan Pemilihan Hotel Bagi Wisatawan di Kota Batu

Berikut adalah keterangan Gambar 1 yang merupakan flowchart Sistem Pendukung Keputusan Pemilihan Hotel Bagi Wisatawan di Kota Batu :

1. Sistem menentukan kriteria

2. User memasukkan prioritas kriteria yang ditampung dalam matriks perbandingan berpasangan

3. Sistem melakukan perhitungan eigen vector

4. Sistem mengecek apakah $C R$ atau konsistensi rasio lebih kecil dari 0,1

5. Jika tidak konsisten maka user harus merubah nilai prioritas kriteria

6. Apabila sudah dinyatakan konsisten, maka bobot yang telah diproses dalam eigen vector menjadi bobot di metode $A H P$

7. Menentukan tipe penilaian yang berupa minimal atau maksimal, berdasarkan pada kriteria dan alternatif yang telah tersedia

8. Kemudian menentukan tipe preferensi dan nilai threshold

9. Sistem melakukan perhitungan indeks preferensi

10. Sistem melakukan perhitungan nilai entering flow, leaving flow dan net flow

11. Sistem menampilkan ranking rekomendasi hotel

\section{Implementasi}

Implementasi adalah penulisan bahasa pemograman pada komputer, agar kode program dapat berjalan sesuai dengan rancangan. Berikut langkah langkah pada tahap implementasi.

\subsection{Instalasi}

Instalasi dimulai dari mempersiapkan codeigniter, selanjutnya memasang MySQL sebagai tempat penyimpanan database.

\subsection{Membuat Skema}

Pada tahapan ini dimulai dengan mendesain skema basis data yang merepresentasikan bentuk tabel pada basis data, sistem manajemen basis data yang digunakan pada penelitian ini adalah mysql.

Berikut beberapa tabel yang terdapat pada Sistem Pendukug Keputusan Pemilihan Hotel bagi Wisatawan di Kota Batu :

1. Rekomendasi hotel user

Berisi hasil rekomendasi dari skala prioritas yang telah dipilih oleh wisatawan dan diolah oleh sistem menggunakan metode AHP dan Promethee.

2. Rekomendasi hotel

Berisi hasil rekomendasi dari skala prioritas yang telah dipilih oleh admin dan diolah oleh sistem menggunakan metode AHP dan Promethee.

\section{Bobot User}

Tabel ini menampung hasil pembobotan yang diuji menggunakan metode AHP, dan telah dinyatakan konsisten. Pengecekan konsistensi didasarkan pada skala prioritas yang telah dipilih oleh wisatawan.

4. Bobot

Tabel ini menampung hasil pembobotan yang diuji menggunakan metode AHP, dan telah dinyatakan konsisten. Pengecekan konsistensi didasarkan pada skala prioritas yang telah dipilih oleh admin.

\section{Operator}

Menampung data admin yang dapat dikelola, seperti diupdate, dihapus dan ditambah datanya melalui fitur register.

6. Normalisasi

Merupakan tabel yang digunakan untuk menyimpan data hasil normalisasi pada tahap pengimplementasian metode promethee.

7. Master fasilitas

Berisi data daftar fasilitas yang tersedia di seluruh hotel berbintang di Kota Batu, sesuai data dari Dinas Pariwisata Kota Batu dan website resmi hotel.

8. Fasilitas

Tabel yang menyimpan data fasilitas pada setiap hotel berbintang yang ada di Kota Batu, sesuai data dari Dinas Pariwisata Kota Batu dan website resmi hotel. 


\section{Master strategis}

Berisi data daftar startegis yaitu daftar objek wisatawa yang dekat dengan hotel berbintang di Kota Batu, sesuai data dari Dinas Pariwisata Kota Batu dan website resmi hotel.

\section{Startegis}

Tabel yang menyimpan data objek wisata yang dekat dengan setiap hotel atau daftar strategis setiap hotel berbintang yang ada di Kota Batu, sesuai data dari Dinas Pariwisata Kota Batu dan website resmi hotel.

11. Alternatif

Berisi data daftar hotel berbintang yang ada di Kota Batu, seperti nama, alamat, nomor telepon dan harga. Data didapat dari Dinas Pariwisata Kota Batu dan website resmi hotel.

\subsection{Membuat Antarmuka}

Proses berikutnya yaitu membuat tampilan yang akan diakses oleh wisatawan dan admin serta mengintegrasikan dengan database yang sebelumnya telah dibuat.

Beberapa tampilan yang diimplementasikan pada Sistem Pendukung Keputusan Pemilihan Hotel adalah sebagai berikut:

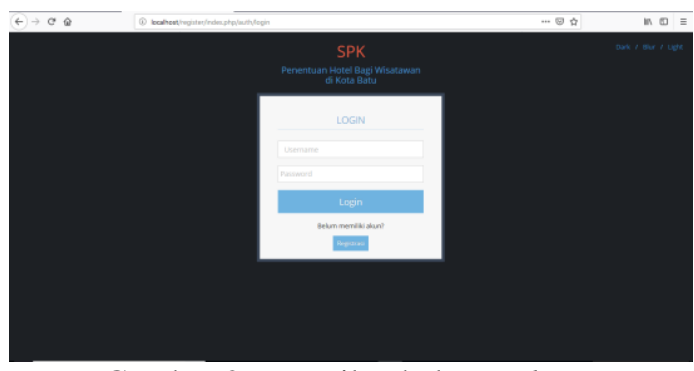

Gambar 2. Tampilan halaman login

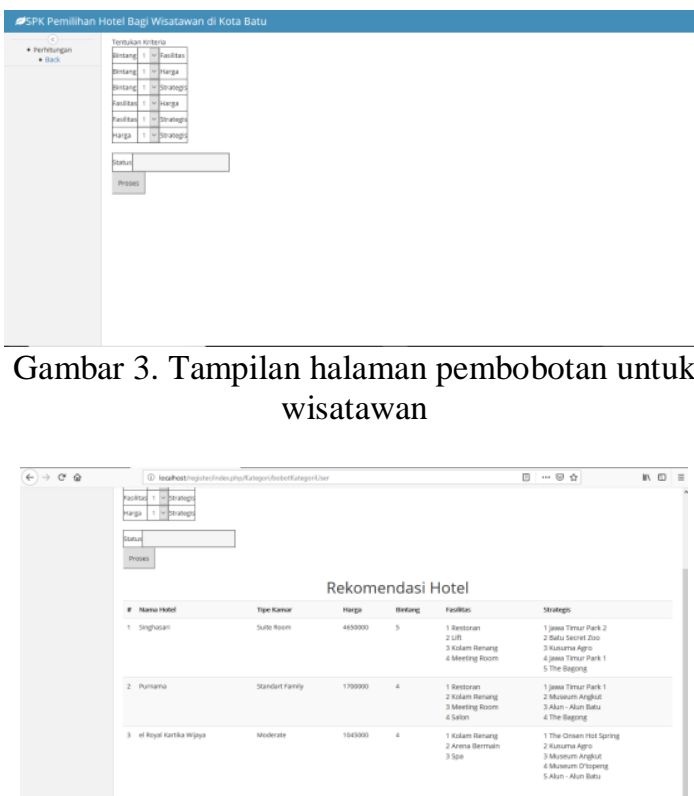

Gambar 4. Tampilan hasil pengolahan data untuk wisatawan

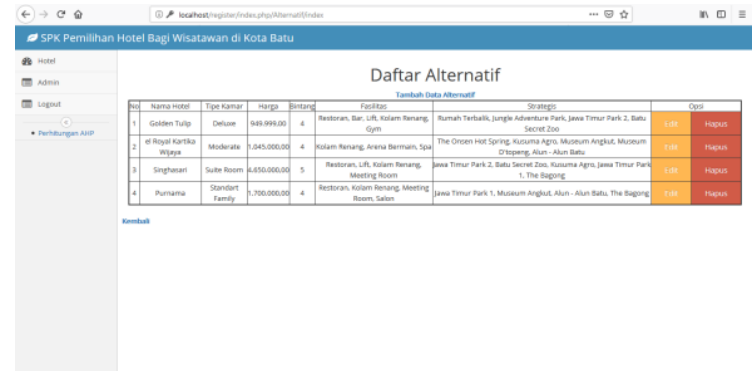

Gambar 5. Tampilan halaman kelola data hotel

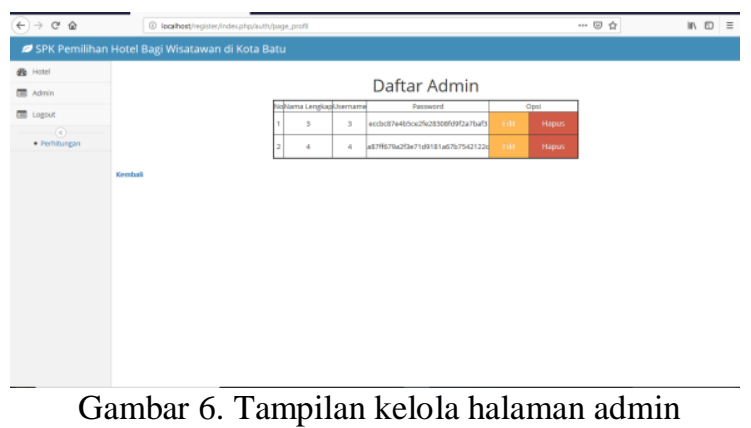

\section{Pengujian}

Metode Pengujian yang dilakukan oleh penulis untuk menguji sistem secara keseluruhan dilakukan dengan cara pengujian fungsional dan uji coba perhitungan. Pengujian dilakukan dengan menjalankan fitur-fitur yang terdapat dalam sistem dan melihat kesesuaian antara rancangan pengembangan dengan implementasi yang telah dilakukan. Proses uji coba perhitungan dilakukan untuk melihat kesesuaian antara hasil perhitungan yang diolah sistem dengan perhitungan yang dilakukan secara manual. Jika kedua perhitungan sesuai maka sistem dapat dinyatakan sesuai.

Berikut fitur-fitur yang akan diuji:

1. Lihat data kategori

2. Tambah data kategori

3. Edit data kategori

4. Hapus data kategori

5. Login

6. Register

7. Pilih skala prioritas

8. Lihat rekomendasi hotel

9. Lihat data alternatif

10. Tambah data alternatif

11. Edit data alternatif

12. Hapus data alternatif

Berikut use case diagram Sistem Pendukung Keputusan Pemilihan Hotel bagi Wisatawan di Kota Batu untuk memberikan gambaran yang lebih jelas mengenai fitur dan hak akses pada setiap pengguna aplikasi. 


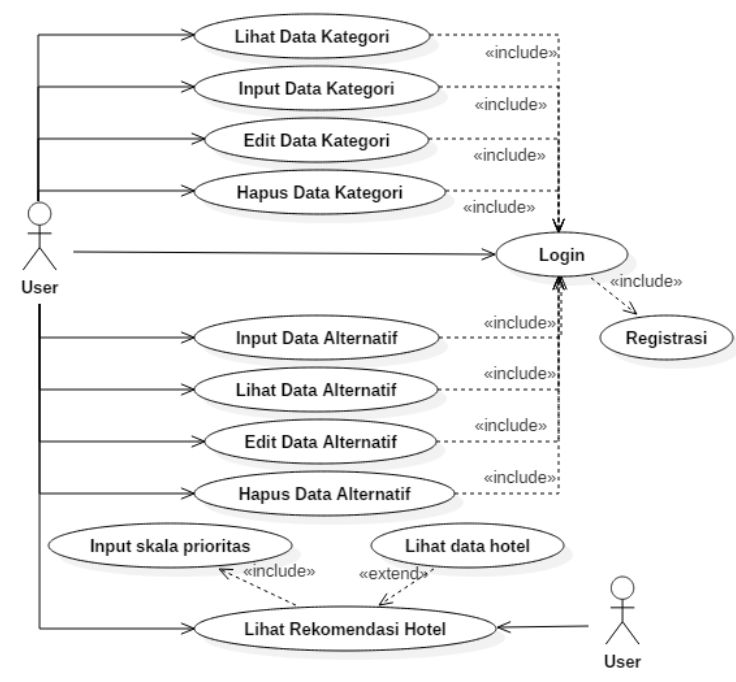

Gambar 9. Use Case Diagram

\section{Kesimpulan dan Saran}

Berdasarkan hasil analisis, perancangan, dan pengujian yang dilakukan, terdapat beberapa kesimpulan didapat yaitu:

1. Tampilan dirasa kurang ramah untuk pengguna

2. Alur program lebih diperjelas, dalam konteks ini tidak semua proses ditampilkan pada sistem.

3. Update data tidak bisa realtime

Berdasarkan penelitian yang dilakukan, dapat diajukan beberapa saran sebagai berikut:

1. Mengembangkan sistem ini dengan platform yang berbeda

2. Membuat interface yang lebih ramah untuk pengguna.

3. Sistem update data secara realtime, agar informasi yang disajikan selalu sesuai.

\section{Daftar Pustaka:}

C. Dicky Sumarsono. (2014): Dahsyatnya Bisnis Hotel Di Indonesia, Gramedia, Jakarta.

E. K. A. W. (2017): Pengembangan Sistem Pendukung Keputusan Penentuan Lokasi Pembangunan Pusat Oleh-Oleh di Kabupaten Mojokerto Menggunakan Metode Promethee. Jurusan Teknologi Informasi Politeknik Negeri Malang

E.Mu dkk. (2017): Understanding the Analytic Hierarchy Process, -: SpringerBriefs in Operations Research, Springer

Ferinda Yuamita dkk. ae968f26205d079725048b. Available: elisa.ugm.ac.id

H. Rasputri. (2018): kumparantravel. Available: https://kumparan.com

I. Richa. (2018): PHRI Minta Segera Ada Moratorium Hotel di Kota Batu, malangtimes.

Available

https://www.malangtimes.com

Mara Destiningrum dkk. (2017): Sistem Informasi Penjadwalan Dokter Berbasis Web dengan Menggunakan Framework Codeigniter (Studi Kasus:Rumah Sakit Yukum Medical Center). TEKNOINFO, vol. 11, no. 2, pp. 30-37

N. A. Tamara. (2017): Pengembangan Aplikasi Pemilihan Kost Di Kota Malang Dengan Metode AHP Dan Promethee. Jurusan Teknologi Informasi Politeknik Negeri Malang

N. Kumar. -. Multi Criteria Decision Making, in Water Resources System Planning and Management Advanced Topics. Bangalore

S. Hambali. (2015): Pengambilan Keputusan Manajemen Menggunakan Analytic Hierarchy Proses (AHP). Available : http://sbm.binus.ac.id/2015/05/25/pengambila n-keputusan-manajemen-mengunakananalytical-hierarchy-process-ahp/

S. N.E. (2016): Pengembangan Sistem Informasi Penentuan Mahasiswa Berprestasi Menggunakan Metode Promethee, Malang". Jurusan Teknologi Informasi Politeknik Negeri Malang 